\title{
Statistical and methodological problems with concreteness and other semantic variables: A list memory experiment case study
}

\author{
Lewis Pollock ${ }^{1}$ (D)
}

Published online: 13 July 2017

(C) The Author(s) 2017. This article is an open access publication

\begin{abstract}
The purpose of this article is to highlight problems with a range of semantic psycholinguistic variables (concreteness, imageability, individual modality norms, and emotional valence) and to provide a way of avoiding these problems. Focusing on concreteness, I show that for a large class of words in the Brysbaert, Warriner, and Kuperman (Behavior Research Methods 46: 904-911, 2013) concreteness norms, the mean concreteness values do not reflect the judgments that actual participants made. This problem applies to nearly every word in the middle of the concreteness scale. Using list memory experiments as a case study, I show that many of the "abstract" stimuli in concreteness experiments are not unequivocally abstract. Instead, they are simply those words about which participants tend to disagree. I report three replications of list memory experiments in which the contrast between concrete and abstract stimuli was maximized, so that the mean concreteness values were accurate reflections of participants' judgments. The first two experiments did not produce a concreteness effect. After I introduced an additional control, the third experiment did produce a concreteness effect. The article closes with a discussion of the implications of these results, as well as a consideration of variables other than concreteness. The sensorimotor experience variables (imageability and individual modality norms) show the same distribution as concreteness. The distribution of emotional valence scores is healthier, but variability in ratings takes on a special significance for this measure because of how the scale is constructed. I recommend that researchers using these
\end{abstract}

Lewis Pollock

lewis.pollock.13@ucl.ac.uk

1 University College London, London, UK variables keep the standard deviations of the ratings of their stimuli as low as possible.

Keywords Concreteness · Semantic variables · List memory · Methodology

Word concreteness has become one of the most studied variables in the psycholinguistic literature. Since Paivio, Yuille, and Madigan (1968) published one of the first large-scale databases of word concreteness norms, "concreteness effects" have emerged in a variety of investigations of various cognitive processes, and a range of theories have been proposed in an attempt to explain these effects. Independent teams of researchers operating over a period of decades have repeatedly shown that concrete words show a processing advantage over abstract words in certain experimental paradigms. For example, concrete words are easier to remember than abstract words (Allen \& Hulme, 2006; Miller \& Roodenrys, 2009; Romani, McAlpine, \& Martin, 2008; Walker \& Hulme, 1999), are easier to make associations with (de Groot, 1989), and are more easily and more thoroughly defined in dictionary definition tasks (Sadoski, Kealy, Goetz, \& Paivio, 1997). Historically, it was claimed that concrete words are responded to more quickly than abstract words in lexical decision tasks (Bleasdale, 1987; James, 1975; Kroll \& Merves, 1985), although more recent experiments have shown no difference (Brysbaert, Stevens, Mandera, \& Keuleers, 2016), or even that abstract words might have an advantage after various other variables have been accounted for (Kousta, Vigliocco, Vinson, Andrews, \& Del Campo, 2011). However, even an abstractness advantage in lexical decision points to the utility of word concreteness as a psycholinguistic variable.

Brain-imaging techniques have also been employed to determine whether the neural systems underpinning concrete 
words and abstract words are distinct (Binder, Westbury, McKiernan, Possing, \& Medler, 2005; Dhond, Witzel, Dale, \& Halgren, 2007; Kounios \& Holcomb, 1994; Pexman, Hargreaves, Edwards, Henry, \& Goodyear, 2007; Sabsevitz, Medler, Seidenberg, \& Binder, 2005). The general consensus from these brain-imaging studies is that there is evidence of a neuroanatomical difference in the processing of concrete versus abstract words.

Psychologists are clearly heavily invested in the investigation of word concreteness, and for good reasons. If there are properties that define a cognitively relevant ontology of concepts, concreteness seems like a good candidate: Something about what constitutes the concept of "elephants" (highly concrete) is probably different from what constitutes the concept of "paradoxes" (highly abstract). However, in this article I will highlight a problem with the concreteness measure, based on a simple statistical summary of the Brysbaert, Warriner, and Kuperman (2013) concreteness norms. I report three replication experiments that together suggest that this problem is not fatal to concreteness research, but also that it should be acknowledged when researchers design their stimuli. I also show that the same problem applies to other variables in semantic databases, such as imageability (Cortese \& Fugett, 2004; Schock, Cortese, \& Khanna, 2012) and individual modality norms (Lynott \& Connell, 2012).

\section{Word concreteness}

A word's concreteness rating is derived by asking a group of participants to rate that word for concreteness on a Likert scale. A low score indicates that a word is highly "abstract," whereas a high rating indicates that a word is highly "concrete." The mean value of all participants' ratings is taken to be an approximation of a word's position on an abstract-concrete continuum. I will now develop some theoretical concerns about the validity of traditional concreteness norms before turning to a statistical analysis of the Brysbaert et al. (2013) database. Consider the job a participant is being asked to do when she is told to rate a word between, say, 1 and 5 on a scale of concreteness. She is told that "concrete words are experienced by the senses," whereas abstract words are not (Paivio et al., 1968). For some words, the interpretation of traditional concreteness norming instructions is relatively straightforward. A participant who is presented with the word "apple" is likely to have seen, touched, smelled, and tasted apples throughout the course of their life, and will unproblematically assign "apple" a high concreteness rating. Similarly, a participant that is presented with the word "serendipity" is likely to reason that since serendipity is a loose association between some coincidental, nonspecified events, and is not something that affords direct sensory experience, the word "serendipity" should be assigned a low concreteness rating. However, what are the properties that a word/concept should have in order for it to be assigned a mid-scale rating? It is difficult to formulate a coherent approach to this task: Can an entity or idea be "half-seen" or "half-touched"? What does it mean to have intermediate sensory experience of an entity or idea? That is to ask: What is a participant telling us about a word when they rate it a 3 out of 5 ? They could mean any one of the following:

1. Adding up all of my sensory experience of this object across all five of the sensory modalities, I realize that I have seen and heard it, but never touched, smelled, or tasted it. So I suppose I'll rate it a 3.

2. One interpretation of this word brings to mind something that cannot be directly experienced, whereas a different interpretation of this word brings to mind something that can be directly experienced. So I suppose I'll rate it a 3 .

3. Sometimes I associate sensory experience with this word, but sometimes I don't. So I suppose I'll rate it a 3.

It is certainly possible to imagine more potential approaches, and there is no empirical basis for selecting one of these approaches over another. Furthermore, it is likely that different participants will generate different interpretations for many of the words in any list of words to be normed. When a participant sees the letter string < deed $>$ presented in isolation, there is no way that a researcher can control for the fact that half of the participants may interpret $<$ deed $>$ as referring to a document associated with proof of property ownership (high concreteness value?), and the other half may interpret it as referring to some unspecified action, perhaps involving some element of heroism (low concreteness value?). Consequently, for a number of words it is just not clear what word/concept the mean concreteness rating is supposed to reflect.

This point on its own might be enough to motivate the avoidance of words with a mean value in the middle of a concreteness-abstractness scale. Given that it is not clear what it is that participants are even telling us when they rate a word a 3 , we might also wonder how often participants actually use values from the middle of the concreteness scale when making their judgments. Recently, Brysbaert et al. (2013) provided a concreteness norm database of 40,000 English words, which dwarfs the previously popular MRC database used in most studies (Coltheart, 1981). This new, larger database allows a statistical analysis of the distributions of concreteness norms across a much larger section of the English lexicon. I now present this analysis and use it to develop the concerns raised in this section. 


\section{Brysbaert et al. (2013) concreteness norms}

Brysbaert et al. (2013) collected a new set of concreteness norms for 40,000 English words. Groups of approximately 25 participants rated subsets of the whole list of 40,000 words on a concreteness scale of 1 (very abstract) to 5 (very concrete). The participants $(n=4,237)$ came from a range of ages, with approximately one third between 17 and 25 years old, and two thirds between 26 and 65 . The mean value of a group of participants' judgments about the concreteness of a stimulus word was assumed to be a useful approximation of that word's position on a hypothesized concrete-abstract continuum. I shall now argue that this is not necessarily the case. The standard deviation of a dataset is a measure of the average distance between all data points in that dataset and the mean value of all data points in the dataset. If every participant rates a word as a 1 (highly abstract), then that word's concreteness rating will have a standard deviation of 0 . However, if half of the participants rated a word as a 1 , but the other half rated the word as a 5 (highly concrete), that word would have a mean concreteness rating of 3 but a standard deviation of 2 . In Likert scale norming tasks, the standard deviation of a set of ratings is therefore a blunt index of the extent to which participants agreed with each other about how a word should be rated.

If a dataset contains 25 numbers (in our case, 25 individual concreteness judgments), all of which are integers between 1 and 5 , then there are a finite number of possible combinations of means and standard deviations for that dataset. Figure 1 below plots all of these possible combinations:

Note how, at the extreme ends of the $x$-axis, only a standard deviation of 0 is possible, because for a mean value to be 1 or 5 , all 25 participants must have rated a word as 1 or 5 , respectively. However, in the middle of the scale the disagreement that is theoretically possible increases, reaching a peak at mean value $\sim 3$, standard deviation $\sim 2$. Crucially, it is still

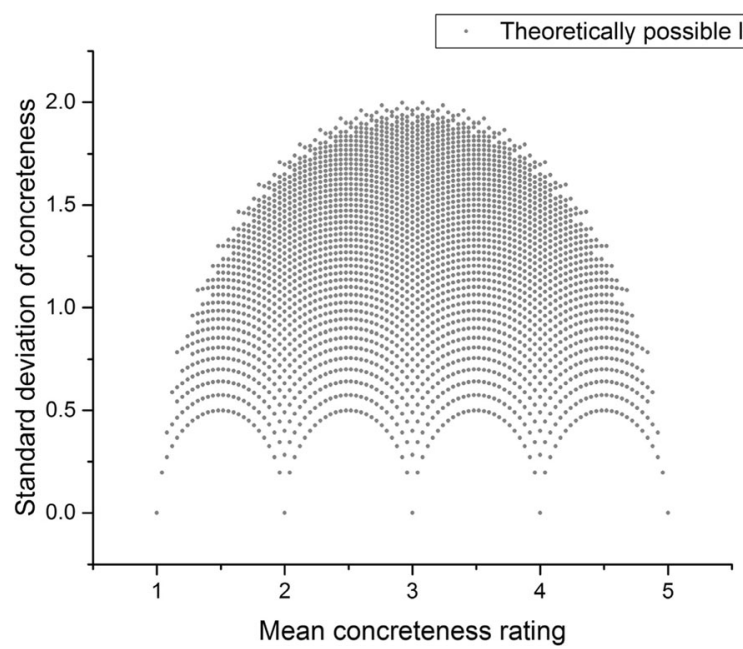

Fig. 1 Theoretically possible locations for words rated between 1 and 5 by 25 different participants theoretically possible for a data point to occur with a mean value located in the middle of the scale, but with a relatively low standard deviation. That is, it is still clearly theoretically possible for participants to more or less consistently agree that a word is of intermediate concreteness.

Now, consider Fig. 2, which plots the actual mean concreteness value and the standard deviation of every noun in the Brysbaert et al. (2013) concreteness norm dataset $(n=$ 14,592 ) over the top of the theoretically possible combinations depicted in Fig. 1.

The pattern is striking. At the extreme concrete end of the scale, many items have high concreteness ratings and relatively low standard deviations, indicating that participants more or less agreed in their judgments about how to rate these words. At the extreme abstract end of the scale, there are likewise words with low concreteness ratings and relatively low standard deviations, although not to the same extent as at the extreme concrete end. However, in the middle of the scale there is an obvious rise in the standard deviation. Only a handful of words have a mean value near 3 and a standard deviation even slightly below 1 . Indeed, a large class of words have a standard deviation well over 1 , ranging from mean values of 1.5 to 4.5 .

This indicates that for a great number of items, participants were not agreeing in their judgments of how concrete a stimulus word was. At mean values of 2 and 4 there are many cases of standard deviations above 1 . Remember that ratings on this scale can only take integer values between 1 and 5 . This means that for many of the words with a mean value of 2 or 4, some participants must have judged these words as belonging at the opposite end of the concreteness scale from the position where the mean value suggests the word belongs. This phenomenon is problematic for the assumption that concreteness should be treated as a continuous variable. This is because in a vast number of cases, participants' judgments tended not to be continuous; instead, they tended to be binary:

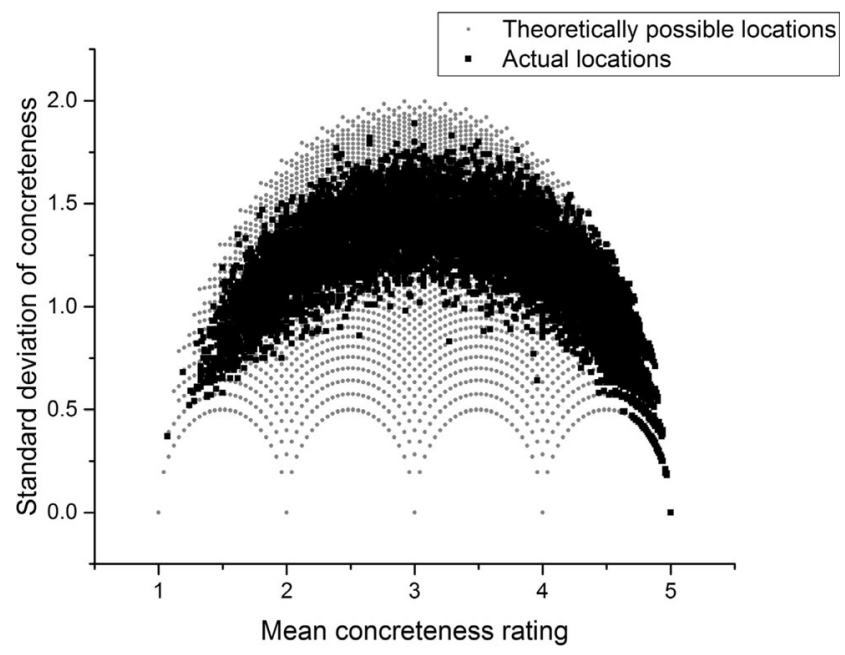

Fig. 2 Theoretical versus actual locations 
Participants were using values of $1,2,4$, and 5 in producing these concreteness norms, and avoided using 3. Furthermore, in many cases participants were judging a word as a 1 (totally abstract), whereas others were judging that same word as a 4 (somewhat concrete).

Given these methodological issues, it might seem surprising that concreteness effects are so widely reported. If measurements for a large section of the hypothesized concreteness spectrum are actually procedural artifacts, it is then unclear what phenomenon it is that concreteness effects are actually indexing. One potential explanation is that generally, when investigating the effect of a variable, researchers try to choose stimuli that maximize a change in this variable, in order to generate the maximum possible effect. It is therefore possible that empirical concreteness research might not suffer too badly from the problem of binary disagreements concerning midscale items, because researchers will have aimed to pick stimuli from the extreme ends of the scale, and these polar items are less subject to disagreement.

However, if it turns out that many experimental stimuli do suffer from the disagreement phenomenon, this poses an explanatory problem concerning the evidence in favor of processing differences between abstract and concrete items. The typical finding is that there are processing advantages for concrete items relative to abstract items, and the typical explanation of this finding is that concrete and abstract items have different neurologically instantiated formats and/or structural relationships. If a significant number of the stimuli included in an abstract or concrete experimental condition actually come from the middle of the concreteness scale, then the typical claim that there are processing differences between concrete and abstract items is no longer supported by the data. This is because words from the middle of the scale must have high standard deviations. This means that only half of the participants who produced the concreteness measure for that word judged it to be abstract, and the other half judged it to be concrete. Therefore, there are no empirical grounds for calling these words "concrete" or "abstract" in the first place.

\section{Stimuli in concreteness experiments: A case study of list memory paradigms}

In this section I plot the stimuli featured in four list memory experimental studies against the entire Brysbaert et al. (2013) database. These studies are Allen and Hulme (2006), Walker and Hulme (1999), Romani et al. (2008), and Miller and Roodenrys (2009). We should note a few things. First, although the replication experiments that I report below feature noun stimuli, and most studies under discussion here also featured nouns, occasionally their stimulus sets featured other word classes alongside nouns. In the case of Allen and Hulme, many of the stimuli in the abstract condition were not nominal. Therefore, to display the maximum number of stimuli for all experiments, I have plotted the entire Brysbaert et al. (2013) database $(n=40,000)$ instead of just the nominal subsection of it. Not all of the stimuli featured in all experiments appeared in the Brysbaert et al. norms, and these stimuli have been omitted from the analysis. Second, the pattern of means and standard deviations is absolutely unchanged when we compare the entire Brysbaert et al. database with the noun subsection of it.

Now, consider Fig. 3. The stimuli featured in Romani et al. (2008) best exemplify the problem, although the intention here is not to single out Romani et al. or any of the other authors under discussion for criticism. The analysis I present here would have been almost impossible to carry out at the time that these experiments were conducted, given that the Brysbaert et al. concreteness database was only published in 2013. In brief, the problem is that the concrete words tend to have low standard deviations, whereas the abstract stimuli tend to have high standard deviations and to be drawn from the middle of the scale, rather than the unequivocally abstract part of the scale. This is potentially problematic for the validity of Romani et al.'s conclusions regarding concreteness effects, because many of the stimuli that made up their abstract stimuli were not unequivocally abstract. For the standard deviations of many of the "abstract" stimuli to be as high as they are-in many cases, well above 1-many participants must have been judging those words to be concrete during the Brysbaert et al. (2013) norming process. Some of the abstract stimuli have standard deviations approaching the theoretical maximum of 2 , indicating maximum disagreement among participants about whether that word is concrete or abstract. To reiterate: Participants could only apply integer values in making their judgments. Therefore, even if a word has a mean concreteness rating of approximately 2 , but also a standard deviation of the rating above 1 , that means that some participants must have been crossing scale halves in making their judgments.

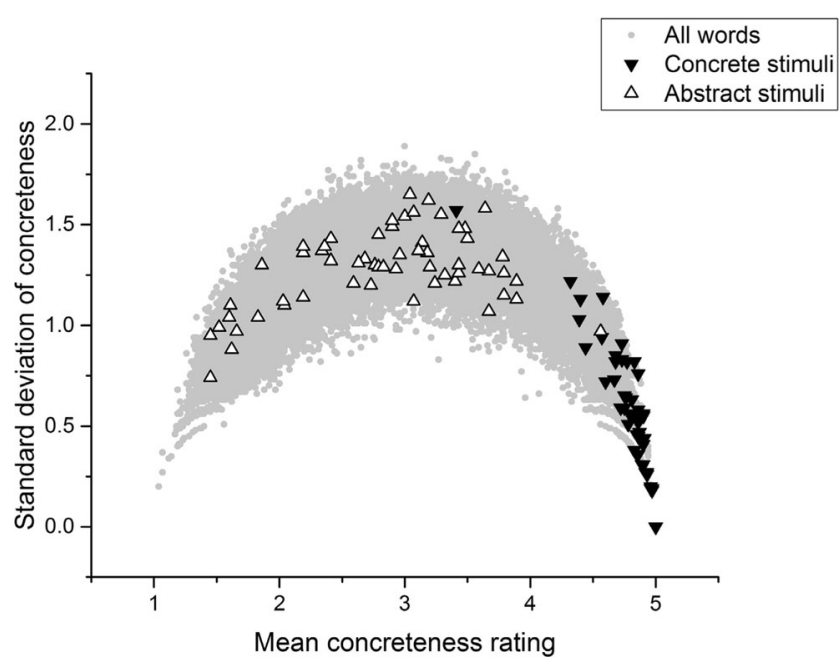

Fig. 3 Romani et al. (2008) stimuli 
Ultimately, it is not clear what comparison is actually being made here. The concrete stimulus lists were more or less unproblematically concrete. However, the abstract stimulus lists contained words drawn from nearly the entire length of the concreteness scale, and also tended to feature words that participants disagreed about how to rate.

Figure 4 depicts the abstract and concrete stimuli featured in Allen and Hulme (2006). Again, many "abstract" stimuli here have standard deviations well above 1 , indicating that people disagreed about whether the words were abstract in the first place. The range of mean ratings of concreteness for the abstract condition is also clearly much higher than in the concrete condition. Once again, a relatively homogeneous group of concrete words has been compared to a heterogeneous group of words about which participants tended to disagree.

Figure 5 plots the stimuli featured in Miller and Roodenrys (2009). Again, there is a marked difference in standard deviations between the concrete and the abstract stimuli. Furthermore, the standard deviations of the abstract stimuli are so high (well above 1 in the majority of cases) that the mean value does not reflect the judgments that participants were actually making.

Finally, consider Fig. 6, which depicts the stimuli featured in Walker and Hulme (1999). The midscale criticism applies least to this set of stimuli, although it is still clearly the case that the concrete stimuli tended to have lower standard deviations than the abstract stimuli. The reasons for this have already been expounded. The upshot is that a skeptic could reasonably argue that these experiments do not actually provide evidence for concreteness effects. The reason is that the comparison being made was meant to be between concrete and abstract items, but the comparison that was actually made was between concrete items, on the one hand, and a group of stimuli about which participants disagree, on the other. It

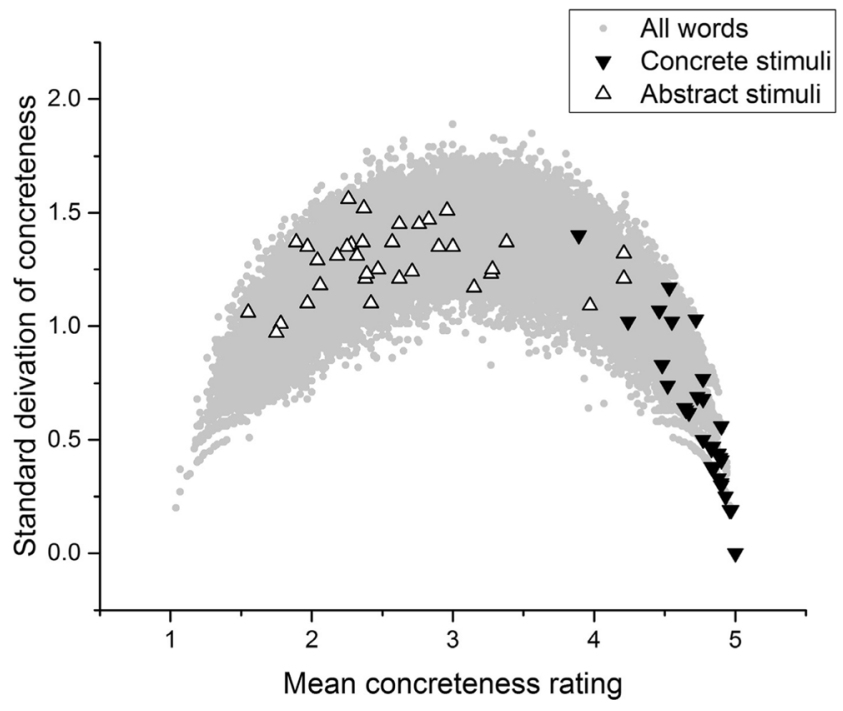

Fig. 4 Allen and Hulme (2006) stimuli

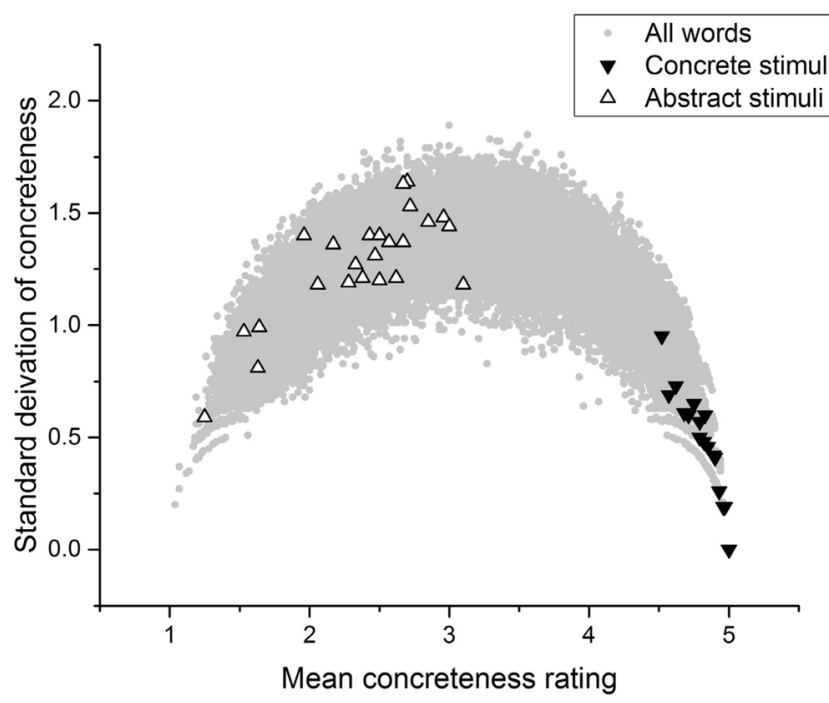

Fig. 5 Miller and Roodenrys (2009) stimuli

could be the case that words that engender disagreement are those that are hard to remember, and that this explains processing differences that have previously been attributed to concreteness/abstractness. The experiments that I report below were designed to test this possibility.

Before moving on to a report of these replication attempts, I wish to point out that list memory paradigms are not a special case when it comes to the properties of "abstract" stimuli. Table 1 presents a number of experimental concreteness studies from a wide variety of paradigms, as well as a summary of the concreteness values and standard deviations of the stimuli featured in their experiments. The abstract-midscale stimulus pattern applies to every single experiment.

Once again, I stress that none of the analysis presented here is intended as a specific criticism of any of these studies. These studies were chosen simply because they reflect a range

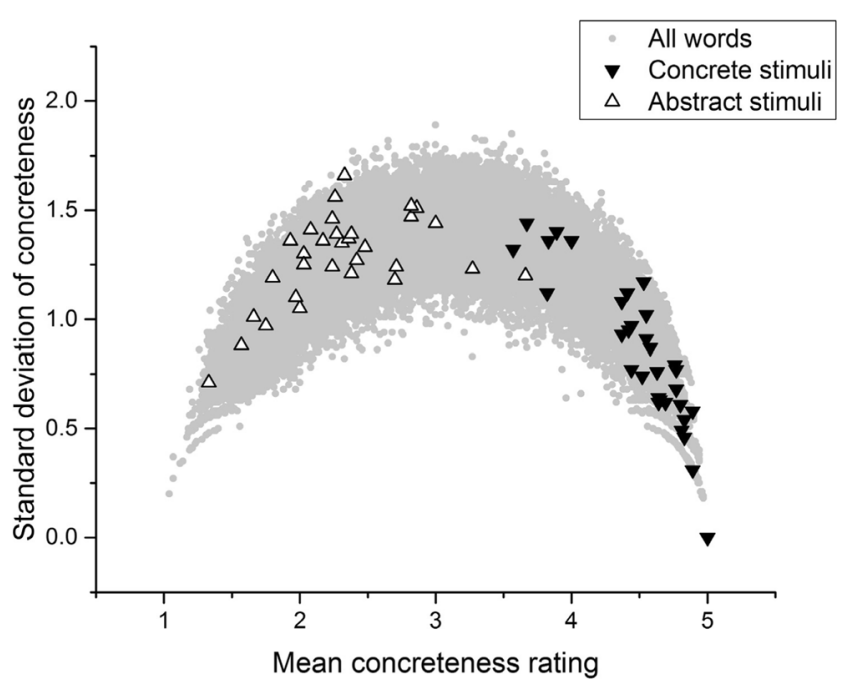

Fig. 6 Walker and Hulme (1999) stimuli 
Table 1 Concreteness statistics in various experimental paradigms

\begin{tabular}{|c|c|c|c|c|c|c|}
\hline \multirow[t]{2}{*}{ Article } & \multirow[t]{2}{*}{ Type of Data } & \multirow{2}{*}{$\begin{array}{l}\text { Experimental } \\
\text { Paradigm }\end{array}$} & \multicolumn{2}{|l|}{ Concrete } & \multicolumn{2}{|l|}{ Abstract } \\
\hline & & & $\begin{array}{l}\text { Mean } \\
\text { Concreteness }\end{array}$ & Mean $S D$ & $\begin{array}{l}\text { Mean } \\
\text { Concreteness }\end{array}$ & Mean $S D$ \\
\hline Kroll \& Merves (1985) & Behavioral & Lexical decision & 4.55 & 0.74 & 2.17 & 1.22 \\
\hline de Groot (1989) & Behavioral & Word association & 4.66 & 0.6 & 2.36 & 1.24 \\
\hline Paivio et al. (1994) & Behavioral & Recall & 4.83 & 0.47 & 2.29 & 1.28 \\
\hline Gee et al. (1999) & Behavioral & Recall & 4.73 & 0.57 & 3 & 1.33 \\
\hline Binder, Nelson, \& Krawczyk (2005) & fMRI & Lexical decision & 4.76 & 0.52 & 2.34 & 1.23 \\
\hline Crutch \& Warrington (2005) & Patient population & Word matching & 4.83 & 0.46 & 3.53 & 1.18 \\
\hline Sabsevitz et al. (2005) & fMRI & Semantic judgment & 4.86 & 0.45 & 2.58 & 1.31 \\
\hline ter Doest \& Semin (2005) & Behavioral & Recall & 4.72 & 0.57 & 2.45 & 1.26 \\
\hline Lee \& Federmeier (2008) & EEG & Semantic judgment & 4.41 & 0.88 & 2.27 & 1.24 \\
\hline Huang et al. (2010) & EEG & Semantic judgment & 3.82 & 1.17 & 2.53 & 1.21 \\
\hline Skipper-Kallal, Mirman, \& Olson (2015) & fMRI & Deep thought & 4.44 & 0.81 & 2.38 & 1.22 \\
\hline Jager \& Cleland (2016) & Behavioral & Lexical decision & 4.62 & 0.64 & 3.29 & 1.19 \\
\hline
\end{tabular}

of experimental paradigms (lexical decision, recall, semantic judgment, word association, and picture-word matching), data types (behavioral, fMRI, electroencephalography [EEG]), and include both neurotypical and patient populations. They also, laudably, included their stimulus sets in their experimental reports, although it is important to note that for Sabsevitz et al. (2005) and Lee and Federmeier (2008) only samples of the stimuli were available. For every study but one listed in Table 1, the mean standard deviation of the stimuli in the concrete condition was below 1 , whereas the mean standard deviation of the stimuli in the abstract condition was above 1. The only exception is Huang, Lee, and Federmeier (2010), in which the standard deviations for both stimulus sets were relatively high. Looking at the distributions displayed above in Figs. 2, 3, 4, 5 and 6, it is clear that the only way these statistics could be obtained is if the midscale disagreement problem applied to all of the abstract stimulus sets of the experiments depicted in the table. I now turn to a report of three new list memory replication experiments in which I attempted to control for the problems that I have outlined so far.

\section{Experiment 1}

The purpose of this experiment was to replicate an experiment reported in Romani et al. (2008) while controlling for the potentially problematic confound between the mean value of a concreteness rating and the standard deviation of that rating. Romani et al. presented participants with lists of words and asked them to recall words from that list immediately after the presentation of the last word of the list. Romani et al. reported that participants were better at recalling lists of words that consisted entirely of concrete words than at recalling lists that consisted entirely of abstract words. Experiment 1 here investigated the reliability of this concreteness effect when the standard deviations of the concreteness value of the words across lists was controlled, while also directly manipulating words' standard deviation in order to ascertain whether the standard deviation itself has a significant effect on task performance. Figure 7 plots the mean concreteness values and standard deviations of concreteness of the concrete and abstract stimuli used in the present experiment in the same way that the stimuli used in previous experiments were plotted in the previous section.

We can see that the contrast in concreteness between conditions is maximized and that the difference in the standard

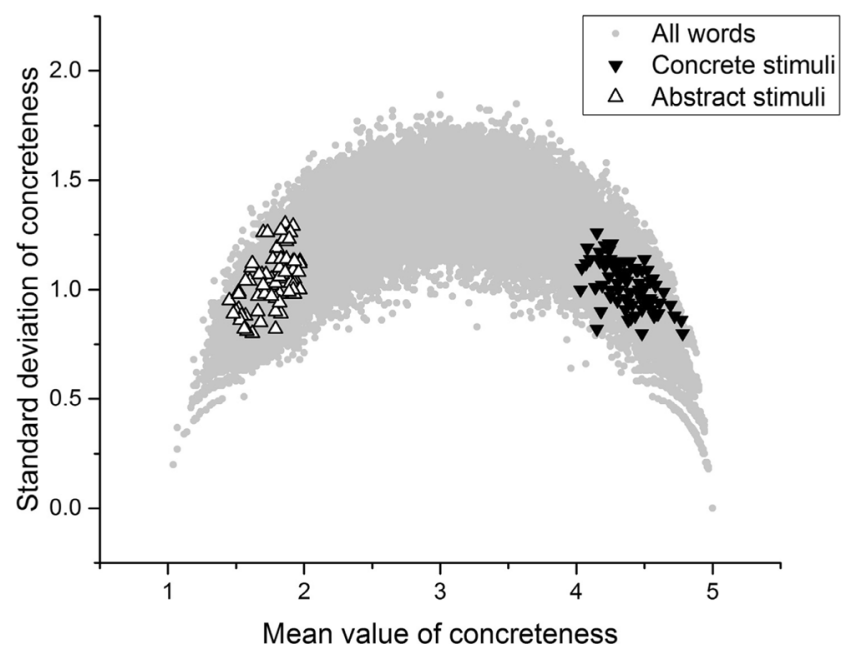

Fig. 7 Concrete and abstract stimuli featured in Experiment 1 
deviations of concreteness ratings is controlled. Of interest is whether the concreteness effect would still occurs when these new controls were enforced.

The specific Romani et al. (2008) experiment replicated here is Experiment $3 \mathrm{~B}$, which is a free-recall task in which participants simply try to recall any word from the list that they can, regardless of order. Romani et al. reported that concreteness effects are stronger in free-recall than in serial-recall tasks, so a free-recall task provides the most robust test of the concreteness effect. An additional two experimental conditions were added: agreement and disagreement conditions. Words in the agreement condition were taken from the middle of the scale and had relatively low standard deviations, and words in the disagreement condition were taken from the middle of the scale and had relatively high standard deviations. Summary psycholinguistic statistics for all conditions are given in the Materials section below. Three comparisons were of interest: concrete versus abstract, concrete versus disagreement, and concrete versus agreement. In this way, the importance of the midscale problem outlined in the section above can be assessed.

\section{Method}

Participants Originally, 60 native speakers of English with no reported neurological disorders were recruited from the University College London SONA psychology pool. Of these, 50 completed the experiment (the other ten either did not turn up or canceled their session). All participants were either awarded course credit or paid $£ 6$ for their time.

Materials Forty lists, each containing eight words, were generated. There were four experimental conditions, each of which comprised ten lists. The stimuli were controlled for the following psycholinguistic variables: standard deviation of concreteness, frequency, age of acquisition, number of phonemes, number of letters, and number of syllables. Table 2 contains the mean values (with standard deviations in parentheses) of each of these variables for each condition.
Psycholinguistic variable information was gathered from Brysbaert et al. (2013), Kuperman, Stadthagen-Gonzalez, and Brysbaert (2012), and the English Lexicon Project (Balota et al., 2007). The stimulus sets were created using MATCH (van Casteren \& Davis, 2007). The four conditions were concrete, abstract, agreement, and disagreement. Concrete lists contained words that had mean values between 4 and 5 on the Brysbaert et al. (2013) concreteness scale. Abstract lists contained words that had mean values between 1 and 2 on the Brysbaert (2013) concreteness scale. The agreement and disagreement lists contained words that had mean values between 2.5 and 3.5 on the Brysbaert et al. (2013) concreteness scale. The concrete, abstract, and agreement lists were constructed such that the standard deviations of the concreteness ratings of the words in those lists were similar, whereas the disagreement condition was formed exclusively of stimuli with high standard deviations. Table 3 contains a sample list from each condition, and full lists of the stimuli featured in all experiments reported in this study are included in the Appendix.

Procedure The experimenter read all of the words from a list one after the other. There was a 2 -s pause between consecutive words being read out. The order of the lists and the order of the words within each list were randomized for each participant. After the experimenter had finished reading out a list, the participant spoke out loud any and all words that he or she could remember from that list. The experimenter recorded every word that the participant spoke. Because this was a free-recall task, the order in which the participants recalled the words did not matter. Participants were not penalized for making errors or substitutions, or for saying a word that had not actually been in the list. The experiment lasted approximately $35 \mathrm{~min}$.

\section{Results}

Table 4 summarizes the mean numbers of words remembered (and standard deviations) by condition.

Table 2 Stimulus properties

\begin{tabular}{|c|c|c|c|c|c|c|c|}
\hline Condition & Mean Concreteness & $S D$ Concreteness & AoA & Zipf Frequency & L Phon & Length & $N$ Syll \\
\hline Concrete & $4.38(0.17)$ & $1.02(0.11)$ & $10.45(2.05)$ & $3.34(0.79)$ & $5.59(0.94)$ & $6.93(1.06)$ & 2.00 \\
\hline Abstract & $1.78(0.14)$ & $1.04(0.12)$ & $10.58(2.09)$ & $3.38(0.83)$ & $5.56(0.93)$ & $6.84(1.17)$ & 2.00 \\
\hline Agree & $3.17(0.7)$ & $1.08(0.07)$ & $10.09(1.9)$ & $3.15(0.85)$ & $5.63(1.03)$ & $6.93(1.21)$ & 2.00 \\
\hline Disagree & $3.1(0.36)$ & $1.65(0.05)$ & $10.23(2.04)$ & $3.13(0.81)$ & $5.76(1.10)$ & $6.9(1.32)$ & 2.00 \\
\hline
\end{tabular}

Mean concreteness: Mean concreteness rating; $S D$ concreteness: The mean standard deviation of the concreteness ratings; AoA: Age of acquisition; Zipf frequency: Word frequency in Zipf units; L Phon: Length of word in phonemes; Length: Length of word in letters; $N$ Syll: Number of syllables 
Table 3 Sample stimulus lists

\begin{tabular}{lllllllll}
\hline Condition & Word 1 & Word 2 & Word 3 & Word 4 & Word 5 & Word 6 & Word 7 & Word 8 \\
\hline Concrete & Beaker & Clinic & Tango & Clothing & Amber & Jackal & Roulette & Survey \\
Abstract & Desire & Mystique & Intent & Vantage & Glory & Nuance & Unease & Motive \\
Agree & Diesel & Roughhouse & Attempt & Whiner & Viewpoint & Freshness & Stampede & Leader \\
Disagree & Slipstream & Audit & Poorhouse & Minute & Rival & Tribune & Abyss & Spectrum \\
\hline
\end{tabular}

The results were analyzed with a mixed-effects model in $\mathrm{R}$ using the lme4 package (Bates, Mächler, Bolker, \& Walker, 2015). The lmertest package was used in order to obtain $p$ values for the comparisons of interest via Satterthwaite approximation (Kuznetsova, Brockhoff, \& Christensen, 2015). The mixed-effects model examined the fixed effect of experimental condition on the number of words remembered per trial, with subjects and items being treated as random effects with varying intercepts.

The statistical contrasts were the abstract, disagreement, and agreement conditions versus the concrete condition. That is, a treatment contrast with the concrete condition representing the baseline condition. Table 5 displays the results of this analysis.

Because three nonindependent hypothesis tests were run on the same data, a Bonferroni correction was applied. Assuming a conventional alpha level of .05, the corrected alpha level was therefore $.05 / 3=.017$. The concrete-abstract contrast was not statistically significant $(p=.13)$. Therefore, there was no evidence for an advantage for concrete over abstract word lists, contrary to the findings of Romani et al. (2008), Walker and Hulme (1999), Allen and Hulme (2006), and Miller and Roodenrys (2009). None of the other contrasts were statistically significant, either, at the Bonferroni-corrected alpha level (concrete vs. agreement, $p=.08$; concrete vs. disagreement, $p=.02$ ). There was therefore no evidence words from the middle of the concreteness scale are simply harder to remember than words from the extreme concrete end of the scale, and there was no evidence that words with high standard deviations in rating are harder to remember than words from the extreme concrete end of the scale. However, a reviewer raised the important point that Experiment 1 suffered from a lack of power, because there were only ten items per condition. This

Table 4 Mean words recalled by condition for Experiment 1

\begin{tabular}{lll}
\hline Condition & $\begin{array}{l}\text { Mean Words } \\
\text { Recalled }(S D)\end{array}$ & $\begin{array}{l}\text { Mean Percentage } \\
\text { Recalled }\end{array}$ \\
\hline Concrete & $4.67(1.35)$ & $58.4 \%$ \\
Abstract & $4.48(1.24)$ & $56 \%$ \\
Disagree & $4.38(1.28)$ & $54.6 \%$ \\
Agree & $4.45(1.35)$ & $55.6 \%$ \\
\hline
\end{tabular}

could be the reason that no statistically significant results were obtained.

To account for this possibility, the data were reanalyzed using a Bayesian model comparison analysis in the BayesFactor package for R (Morey, Rouder, \& Jamil, 2015) with the default settings and priors. If the results of the frequentist analysis presented in the preceding paragraphs were due to low power, then the Bayes factors produced by this analysis are likely to be between $1 / 3$ and 3 , which would indicate that the data do not decide the issue either way.

Kruschke (2011, p. 310) argued that the Bayes factor generated from a model comparison analysis of an experimental design with multiple conditions may be misleading for various reasons. Therefore, the total results dataset of Experiment 1 was partitioned into three smaller datasets that reflected the pairwise comparisons of interest between the conditions: one concrete-abstract comparison, one concrete-agree comparison, and one concrete-disagree comparison. In every case, a model including a parameter for the fixed effect of condition was compared to a null model that featured only subjects and items as random effects. The resulting Bayes factors for each comparison were concrete versus abstract, 0.32 ; concrete versus agree, 0.38 ; concrete versus disagree, 0.66 . For the concrete-abstract comparison, there is marginal evidence in favor of a null effect $(\mathrm{BF}=0.32)$. For the other two comparisons, the Bayes factor indicates that the data do not decide between the null or alternative models. Taken together with the frequentist analysis presented previously (all $p$ values above the threshold for statistical significance), these results suggest no difference in recall between the concrete and abstract conditions. However, the evidence for a null difference in the other comparisons is inconclusive.

Before moving on to the second replication experiment, it is important to note a shortcoming of Experiment 1 that may have affected the results. The standard deviations of the concreteness ratings of both the concrete and abstract stimuli were relatively high: above 1 , in many cases. It could be that, given the concerns raised in previous sections, neither condition provided an accurate sample from the truly concrete or abstract sections of the scale. In the second experiment that I will report, the standard deviations of the conditions were more tightly constrained so that in the concrete and abstract conditions, all standard deviations were below 1 . 
Table 5 Summary of mixed-effects model for Experiment 1

\begin{tabular}{llllllll}
\hline Fixed Effects & Effect Estimate & Error & $d f$ & $t$ & $p$ & $\begin{array}{l}\text { Lower 95\%CI } \\
\text { for Effect }\end{array}$ & $\begin{array}{l}\text { Higher 95\%CI } \\
\text { for Effect }\end{array}$ \\
\hline Abstract & -.19 & -.12 & 39.25 & -1.56 & .13 & -.43 & .05 \\
Agree & -.22 & -.12 & 39.25 & -1.79 & .08 & -.46 & .03 \\
Disagree & -.29 & -.12 & 39.25 & -2.42 & .02 & -.54 & -.05 \\
\hline
\end{tabular}

\section{Experiment 2}

Paivio, Walsh, and Bons (1994) presented participants with lists consisting of both concrete and abstract word pairs and reported that concrete word pairs were recalled better than abstract word pairs. This effect has been obtained in many paired-associate learning experiments (Begg, 1972; Nelson \& Schreiber, 1992; Paivio, Khan, \& Begg, 2000; Paivio et al., 1994). Paivio et al. employed a range of different manipulations across two experiments. In this replication I focused on the simplest version of this paradigm, which is a free-recall task, in order to make the results maximally comparable to those of Experiment 1 above. The aim of the present experiment was to test whether a concreteness effect still occurs if the contrast between concrete and abstract stimuli is maximized and the standard deviations of their concreteness scores are controlled. In addition to the concrete and abstract conditions featured in the paired-associate learning studies mentioned in this section, the present experiment also included a midscale condition to provide a second test of the hypothesis that high-standard-deviation midscale words are harder to remember than words from the concrete end of the concreteness scale.

\section{Method}

Participants Sixty native speakers of English with no reported neurological disorders were recruited from the Prolific Academic website. All participants were paid $£ 6$ for their time.

Materials Figure 8 depicts the means and standard deviations of the concreteness ratings for the concrete and abstract stimuli in Experiment 2. Table 6 displays the psycholinguistic characteristics of the stimuli featured in the experiment, by condition.

In Experiment 2 the additional control variable of mean bigram frequency was introduced, because participants would be reading and writing words as opposed to hearing and speaking them. There were eight pairs of words in each condition, and therefore each condition included 16 words, for a total of 24 critical item pairs overall.

Procedure Participants undertook the experiment online via a Qualtrics survey distributed over the Prolific Academic service. Participants were presented with pairs of words, one after the other. Following Marschark and Hunt (1989) and Paivio et al. (1994), each pair of words was presented on the participant's computer screen for $8 \mathrm{~s}$. Eight pairs were presented in each of the three conditions, and all pairs were presented in a randomized nonblocked order for each participant. The ordering of the words in each pair from left to right on the computer screen was not randomized. At the beginning and end of the list, three pairs of filler items were included in order to soak up primacy and recency effects. Participants also received a short practice trial with words not included in the main experiment, to ensure that they understood the task and that their computers and Internet connections were working properly. Once the list of pairs was finished, participants could type out any and all words that they remembered from the list. Once they were finished, they pressed a "Submit" button that ended the experiment. There were three experimental conditions: A word pair could consist of concrete, abstract, or midscale "disagreement" items. The experiment lasted approximately $15 \mathrm{~min}$.

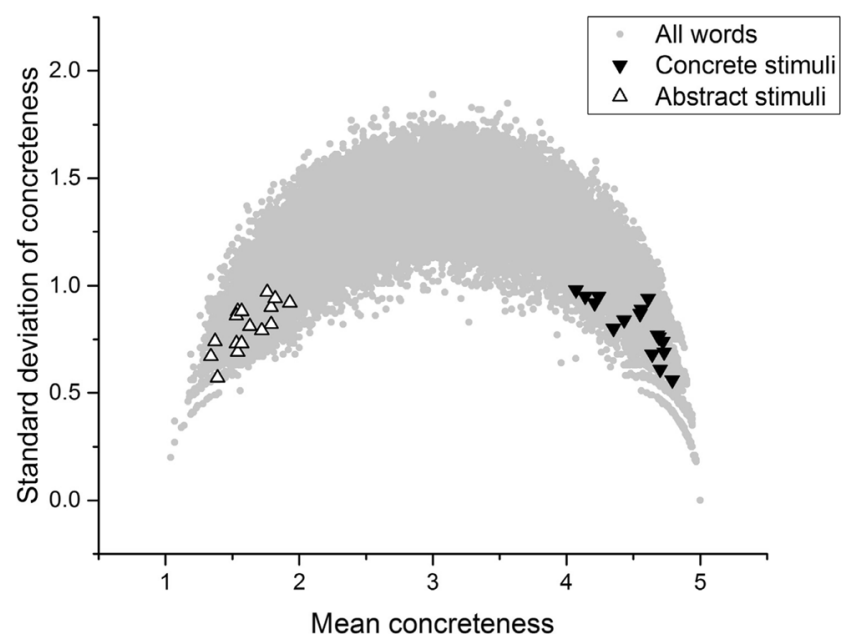

Fig. 8 Concrete and abstract stimuli featured in Experiment 2 
Table 6 Summary of stimulus characteristics for Experiment 2

\begin{tabular}{lllllllll}
\hline Condition & Mean Concreteness & SD Concreteness & AOA & Zipf Frequency & L Phon & $N$ Syll & Length & BG Mean \\
\hline Concrete & $4.51(0.23)$ & $0.91(0.13)$ & $9.92(1.9)$ & $3.54(0.56)$ & $4.75(0.2)$ & $1.75(0.43)$ & $6.125(1.41)$ & $3,573(1,151)$ \\
Abstract & $1.61(0.17)$ & $0.81(0.11)$ & $10.04(1.64)$ & $3.48(0.69)$ & $5.25(1.44)$ & $1.75(0.43)$ & $6.44(1.5)$ & $3,457(1,176)$ \\
Disagreement & $3(0.23)$ & $1.33(0.02)$ & $9.78(1.95)$ & $3.72(0.78)$ & $5.75(1.48)$ & $1.81(0.39)$ & $6.38(1.45)$ & $3,218(957)$ \\
\hline
\end{tabular}

Mean concreteness: Mean concreteness rating; $S D$ concreteness: The mean standard deviation of the concreteness ratings; AoA: Age of acquisition; Zipf frequency: Word frequency in Zipf units; L Phon: Length of word in phonemes; $N$ Syll: Number of syllables; Length: Length of word in letters; BG mean: Mean bigram frequency

\section{Results}

Table 7 displays the mean numbers of words remembered across conditions in Experiment 2.

The numbers of words recalled out of 16 were low, but the variability across participants was large, as indicated by the relatively high standard deviations of the mean numbers of words recalled. This suggests floor effects for some participants. Second, the mean number of words in the abstract condition was numerically larger than that in the concrete condition $(3<3.43)$, so already we have failed to find evidence in favor of a concrete stimulus advantage in paired-associate learning. Finally, the difference between the means of the concrete and disagree conditions was miniscule (3 vs. 3.05, respectively).

The data were analyzed using a generalized linear mixed model fit by maximum likelihood (Laplace approximation) using the glmer function from the lme4 package in R. The dependent variable in this analysis was therefore the likelihood of a participant recalling any word. ${ }^{1}$ Subjects and items were included as random effects with varying intercepts, and the fixed effect of condition was the effect of interest. Both abstract and disagree conditions were compared to the concrete condition. The results of this analysis are presented in Table 8.

Experiment 2 generated no statistically significant effects: $p=.2$ for the concrete-abstract contrast, and $p=.88$ for the concrete-disagree contrast. This pattern of results is the same as that found in Experiment 1: Under conditions that should have made a concreteness effect stronger, such an effect was not obtained. However, ultimately we should be cautious in drawing any conclusions from the results of Experiment 2, because floor effects may have obscured any differences between conditions.

\footnotetext{
${ }^{1}$ A reviewer noted that analyzing the data in this way meant that this experiment was arguably no longer a paired-associate learning task, presumably because it did not account for the paired relationship between the words. In their free-recall analyses, Paivio et al. (1994) calculated the proportions of words remembered and conduct by-subjects and by-items ANOVAs on these proportions. These analyses also ignored word pair relationships and produced concreteness effects, so I think we would still expect the analysis presented here to produce a concreteness effect.
}

\section{Interim summary}

Experiments 1 and 2 did not produce a concreteness effect. This is worrying, given the concerns about the typically high standard deviations of abstract stimuli outlined above. If we increased a difference between conditions on some linear measure, we would not expect experimental effects based on this measure to disappear. However, Kousta, Vinson, and Vigliocco (2009) showed that words with a high emotional valence (whether positive or negative) enjoy a processing advantage over words with neutral emotional valance. ${ }^{2}$ Abstract words tend to be rated higher for emotional valance than concrete words, and this variable was not controlled in Experiment 1 or 2 . Thus, it could be that a confound in the stimuli used in Experiments 1 and 2 obscured any concreteness effect. Warriner et al.'s (2013) emotional valance norms for $\sim 14,000$ English words would allow us to check this possibility. Emotional valance is rated on a scale of 1 (highly negative) to 9 (highly positive), with a score of 5 indicating an emotionally neutral word. Given that either emotional positivity or negativity results in a processing advantage, the absolute value of 5 minus the emotional valance of a word provides a simple linear measure of emotional valance that ignores polarity $(0=$ totally neutral, $4=$ highly emotionally valenced). Table 9 presents the mean absolute emotional valences of the stimuli featured in Experiments 1 and 2.

The words in the concrete and midscale conditions were indeed less emotionally valenced than those in the abstract conditions in both experiments, so this might explain the null results obtained from Experiments 1 and 2.

Another potential issue is that the words featured in Experiments 1 and 2 were of relatively low frequency (between 3 and 4 on the Zipf scale), so it could be that participants did not know all of the words. ${ }^{3}$ This could have obscured any effect of manipulating concreteness. Brysbaert et al. (2013) provided a measure of how many of their participants reported that they knew a word. Table 10 below displays the mean percentages of participants who reported knowing a word for each condition in Experiments 1 and 2.

\footnotetext{
${ }^{2}$ My thanks to an anonymous reviewer for bringing this to my attention.

${ }^{3}$ Again, my thanks to an anonymous reviewer for pointing this out.
} 
Table 7 Mean words recalled by condition in Experiment 2

\begin{tabular}{lll}
\hline Condition & $\begin{array}{l}\text { Mean Words } \\
\text { Recalled }\end{array}$ & $\begin{array}{l}\text { Mean Percentage } \\
\text { Recalled }\end{array}$ \\
\hline Concrete & $3(2.73)$ & $18.6 \%$ \\
Abstract & $3.43(3.07)$ & $21.5 \%$ \\
Disagree & $3.05(2.84)$ & $19.1 \%$ \\
\hline
\end{tabular}

These percentages are high, so it is likely that the number of participants in Experiments 1 and 2 who did not know a word was very low. However, it would obviously be preferable if only words with known percentages of $100 \%$ were used. Unfortunately, for reasons detailed in the General Discussion below, enforcing this control raised new problems. I now report an additional list memory experiment that controlled for emotional valence, in order to provide a better test of the robustness of the concreteness effect.

\section{Experiment 3}

Experiment 3 was a free-recall list memory experiment in the vein of Experiment 1. There were three changes to the paradigm. First, six-word lists were used instead of eight-word lists. This change was made so that more trials per condition (15 in Exp. 3 vs. 10 in Exp. 1) could be fitted into roughly the same amount of time. Romani et al. (2008) and Miller and Roodenrys (2009) both reported concreteness effects with sixword lists. Second, the words were presented visually, and participants wrote out the words at the end of a list instead of speaking them out loud. This change was made because to maximize efficiency, the experiment was run over the Internet using the Gorilla.sc platform. Finally, only three conditions were included: concrete, abstract, and midscale words with high standard deviations.

\section{Method}

Participants A total of 70 participants were recruited from the Prolific Academic website. Of these, 62 completed the experiment. The other eight did not respond to every trial, and so were excluded. The experiment was delivered via Gorilla.sc

Table 8 Summary of a generalized linear mixed model analysis of Experiment 2

\begin{tabular}{lllll}
\hline Effect & Effect Estimate & Std. Error & $z$ & $p$ \\
\hline Abstract & .19 & .15 & 1.3 & .2 \\
Disagree & .02 & .15 & .15 & .88 \\
\hline
\end{tabular}

Table 9 Emotional valences of stimuli featured in Experiments 1 and 2

\begin{tabular}{lllll}
\hline Experiment & Concrete & Abstract & Disagree & Agree \\
\hline 1 & 0.82 & 1.17 & 0.88 & 1.15 \\
2 & 0.91 & 1.61 & 0.99 & N/A \\
\hline
\end{tabular}

and lasted approximately $35 \mathrm{~min}$. Participants were paid $£ 5$ for their time.

Materials The stimuli were controlled for the following psycholinguistic variables: standard deviation of the concreteness rating, frequency, age of acquisition, number of syllables, number of letters, mean bigram frequency, and emotional valence. Table 11 contains the mean values (with standard deviations in parentheses) of each of these variables for each condition, as well as the mean percentages of people in the Brysbaert et al. (2013) norms who reported knowing the words in each condition.

There were three experimental conditions: concrete, abstract, and midscale. There were 15 six-word lists in each condition.

Procedure Participants were presented with words in sequence one at a time in the center of their computer screens. As in Romani et al.'s (2008) visual paradigms, each word remained on the screen for $3 \mathrm{~s}$. After each list had been presented, participants typed out any and all words that they could remember. They were told that the order of the words did not matter and not to worry about spelling. Participants received two practice trials in order to ensure that they understood how to complete the experiment. The orders of the lists and of the words within each list were randomized for each participant.

\section{Results}

Table 12 summarizes the mean numbers of words remembered (and standard deviations) by condition.

The results from Experiment 3 were analyzed in the same way as the results from Experiment 1. Both frequentist and Bayesian analyses are presented. Table 13 displays the results

Table 10 Mean percentages of participants who reported in Brysbaert et al. (2013) knowing the words featured in Experiments 1 and 2

\begin{tabular}{lllll}
\hline Experiment & Concrete & Abstract & Disagree & Agree \\
\hline 1 & $98.5 \%$ & $98.3 \%$ & $97.7 \%$ & $98.5 \%$ \\
2 & $99.5 \%$ & $99.1 \%$ & $98 \%$ & N/A \\
\hline
\end{tabular}


Table 11 Summary of stimulus characteristics for Experiment 3

\begin{tabular}{llllllllll}
\hline Condition & $\begin{array}{l}\text { Mean } \\
\text { Concreteness }\end{array}$ & $\begin{array}{l}\text { SD } \\
\text { Concreteness }\end{array}$ & AoA & $\begin{array}{l}\text { Zipf } \\
\text { Frequency }\end{array}$ & N Syll & Length & $\begin{array}{l}\text { BG mean } \\
\text { Absolute } \\
\text { Valence }\end{array}$ & $\begin{array}{l}\text { Percent } \\
\text { Known }\end{array}$ \\
\hline Concrete & $4.55(0.17)$ & $0.81(0.12)$ & $10.11(1.28)$ & $3.41(0.48)$ & $2.42(0.86)$ & $7.63(1.79)$ & $3,649(1,134)$ & $1.12(0.77)$ & $99 \%$ \\
Abstract & $1.61(0.15)$ & $0.85(0.11)$ & $10.2(1.95)$ & $3.54(0.72)$ & $2.53(0.89)$ & $7.63(1.95)$ & $3,710(1,208)$ & $1.15(0.78)$ & $99 \%$ \\
Midscale & $3.02(0.26)$ & $1.51(0.77)$ & $10.11(1.99)$ & $3.53(0.72)$ & $2.54(0.86)$ & $7.57(1.89)$ & $3,737(1,184)$ & $1.15(0.77)$ & $98.7 \%$ \\
\hline
\end{tabular}

Mean concreteness: Mean concreteness rating; $S D$ concreteness: The mean standard deviation of the concreteness ratings; AoA: Age of acquisition; Zipf frequency: Word frequency in Zipf units; $N$ Syll: Number of syllables; Length: Length of word in letters; BG mean : Mean bigram frequency; Absolute Valence: Absolute value of 5 minus the Warriner et al. (2013) emotional valence score.

of a mixed-effects linear model with a fixed effect of condition and random intercepts for subjects and items.

After controlling for the effects of emotional valence, these results are much more encouraging for the status of concreteness as a useful psycholinguistic variable. The concrete-abstract comparison is statistically significant at $p=.003$, and the difference is in the direction we would expect. The contrast between the concrete and midscale conditions was not statistically significant $(p=.08)$. Because this experiment still featured a relatively small number of items, a Bayesian model comparison analysis was deployed in an attempt to offset a potential lack of power. Again, the default settings and priors of the BayesFactor package were used. As in Experiment 1, the results from Experiment 3 were split into subsets so that the abstract and midscale conditions would be compared to the concrete condition individually. The resulting Bayes factors for each comparison were concrete versus abstract, 5.85; concrete versus midscale, 0.47. For the concrete-abstract comparison, the Bayesian analysis is comparable to the frequentist analysis: A model containing an effect of condition is 5.85 times more likely given the data than a model without this effect, which is quite strong evidence in favor of a concreteness effect. However, the concrete-midscale analysis was inconclusive. One thing to note is that Experiment 3 featured words with similar rates of knowledge to those in Experiments 1 and 2. Experiment 3 produced a concreteness effect, so this might partially allay concerns that Experiments 1 and 2 produced null results because participants did not know the words used. I now turn to a general discussion of these results in light of the issues discussed in the introductory section on concreteness norms, as well as a consideration of other psycholinguistic variables (imageability, modality exclusivity norms, and emotional valence).

Table 12 Mean words recalled by condition for Experiment 3

\begin{tabular}{lll}
\hline Condition & $\begin{array}{l}\text { Mean Words } \\
\text { Recalled }(S D)\end{array}$ & $\begin{array}{l}\text { Mean Percentage } \\
\text { Recalled }\end{array}$ \\
\hline Concrete & $4.06(1.31)$ & $67.7 \%$ \\
Abstract & $3.7(1.25)$ & $61.7 \%$ \\
Midscale & $3.85(1.28)$ & $64.2 \%$ \\
\hline
\end{tabular}

\section{General discussion}

The first two experiments did not produce a concreteness effect, but these experiments featured a confound: The abstract stimuli had higher emotion ratings than the concrete stimuli. Experiment 3 controlled for emotional valence, and the typical concreteness effect reemerged. This highlights the importance of controlling for emotional valence in list memory paradigms. There were no statistically significant differences between the concrete conditions and the midscale conditions in any experiment. This demonstrates that researchers who are interested in the concreteness effect should maximize the contrast between concrete and abstract stimuli and keep the standard deviations of their stimuli low (below 1) in order to maximize their chances of detecting an effect.

It might seem curious that, given that other list memory studies have revealed concreteness effects when comparing mostly concrete stimuli with mostly high-standard-deviation midscale stimuli, no such effect was obtained in any of the experiments reported here. As I argued when discussing the Brysbaert et al. (2013) norms, the middle of the concreteness scale is marked by a high degree of variability that is difficult to interpret. One of the aims of this article was to test the possibility that words that people agree about how to rate are easier to remember than words that people disagree about how to rate. The three experiments reported here do not provide evidence either way on this point: $p$ values above .05 (corrected) and Bayes factors between 1/3 and 3 for the concrete-midscale comparisons indicate evidence for neither the null nor the alternative hypothesis. The most likely reason for this is a lack of power: The experiments presented here did not feature many stimuli per condition. However, as I will discuss below, this problem is harder to address than might first appear. Furthermore, the abstract conditions in the experiments of Romani et al. (2008), Walker and Hulme (1999), Miller and Roodenrys (2009), and Allen and Hulme (2006) were not entirely made up of midscale stimuli. So if there is a concreteness effect in list memory experiments, the abstract-concrete comparisons in these previous experiments would be more likely to detect it than were the concrete-midscale comparisons reported here. 
Table 13 Summary of frequentist mixed-effects model for Experiment 3

\begin{tabular}{llllllll}
\hline Fixed Effects & Effect Estimate & Error & $d f$ & $t$ & $p$ & $\begin{array}{l}\text { Lower 95\% } \\
\text { CI for Effect }\end{array}$ & $\begin{array}{l}\text { Higher 95\% } \\
\text { CI for Effect }\end{array}$ \\
\hline Abstract & -.37 & .12 & 44.34 & -3.11 & .003 & -.61 & -.13 \\
Midscale & -.21 & .12 & 44.34 & -1.79 & .08 & -.45 & .03 \\
\hline
\end{tabular}

This issue aside, in light of my arguments regarding Brysbaert et al. (2013), we should probably avoid using midscale words on purely theoretical grounds: It is unclear what an individual concreteness rating is even measuring when it has a high standard deviation. A reviewer raised the point that abstract words tend to have more variable meanings than concrete words, so more variability in their ratings might be expected. This may be true, but I think it somewhat misses the point. If there is any point in using the concreteness measure (or the other measures I discuss below), we have to take our participants' ratings seriously. If a word in the middle of the scale has a standard deviation above 1, that means a significant number of participants judged it to be concrete. Thus, there isn't a basis for putting that word in the "abstract" category: It does not make sense to pay attention to only half of the participants' judgments. There is another potential issue, even if we make sure to restrict our "abstract" stimuli to mean ratings of 2 or below. Typically, concreteness research has focused on nouns rather than adjectives or verbs. Even starting with a set of 40,000 words, the number of nouns in the Brysbaert et al. (2013) norms that (1) have a mean rating of 2 or below (i.e., are highly abstract), (2) have a standard deviation of 1 or below, and (3) were known by $100 \%$ of the norming population is only 275 . Of these, a small but nontrivial number are either idiomatic fragments ("amuck") or morphologically complex rarities ("purposefulness") that we might be reluctant to include in stimulus lists. In contrast, 2,888 well-known nouns have mean ratings of 4 or above and standard deviations below 1 .

I think this fact should also motivate caution concerning the utility of the concreteness measure. Ultimately, the measure is supposed to tap into a fundamental, neuropsychologically real distinction between different kinds of concepts. It is worrying that the rating is only interpretable for a small number of nominal "concepts" at the abstract pole. However, it is still the case that Experiment 3 produced a concreteness effect. At the very least, we can say that there is some evidence that samples of these "truly" abstract words tend to be harder to remember than highly concrete words.

I turn now to a discussion of other semantic psycholinguistic variables. The midscale variability problem applies to other variables that measure sensorimotor experience. This is not surprising, because these variables are derived in much the same way as concreteness (by taking the mean value of a set of individual judgments about the depth of sensorimotor experience). This is especially significant because it shows that nothing about the Brysbaert et al. (2013) concreteness norms is deficient. Instead, the problems I have identified here are general to a whole class of psycholinguistic measures. Figure 9 presents a mean-standard deviation plot of the imageability ratings of 6,000 words, amalgamated from two databases (Cortese \& Fugett, 2004; Schock et al., 2012). Imageability is a measure of how easy it is to generate a mental image of the referent of a word, and this variable is so highly correlated with concreteness that the two have often been used interchangeably in the literature.

The distribution is identical to that of the concreteness measure. A similar pattern emerges for Lynott and Connell's (2012) modality exclusivity norm (MEN). MEN essentially measures the same thing as concreteness, but it provides more information because it features ratings for all five primary sensory modalities (sight, sound, touch, taste, and smell). A low rating indicates that the referent of a word offers little experience in a given modality; a high rating indicates that a referent offers a lot of experience. Each word is rated on all five modalities. This results in a five-element vector from which various measures can be derived (mean sensory experience, maximum sensory experience, Euclidean distance from origin, etc.). Figure 10 displays mean-standard deviation plots of all 400 words in the MEN for the five sensory modalities.

What is striking here is that even with just 400 words, the familiar shape of the distribution is clearly apparent. I do not

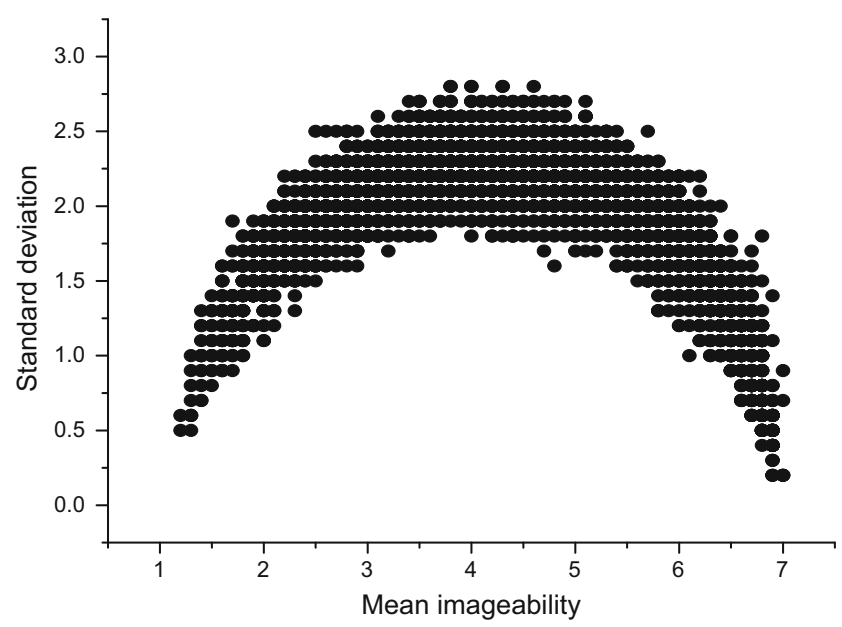

Fig. 9 Means and standard deviations of imageability ratings for 6,000 words (Cortese \& Fugett, 2004; Schock et al., 2012) 

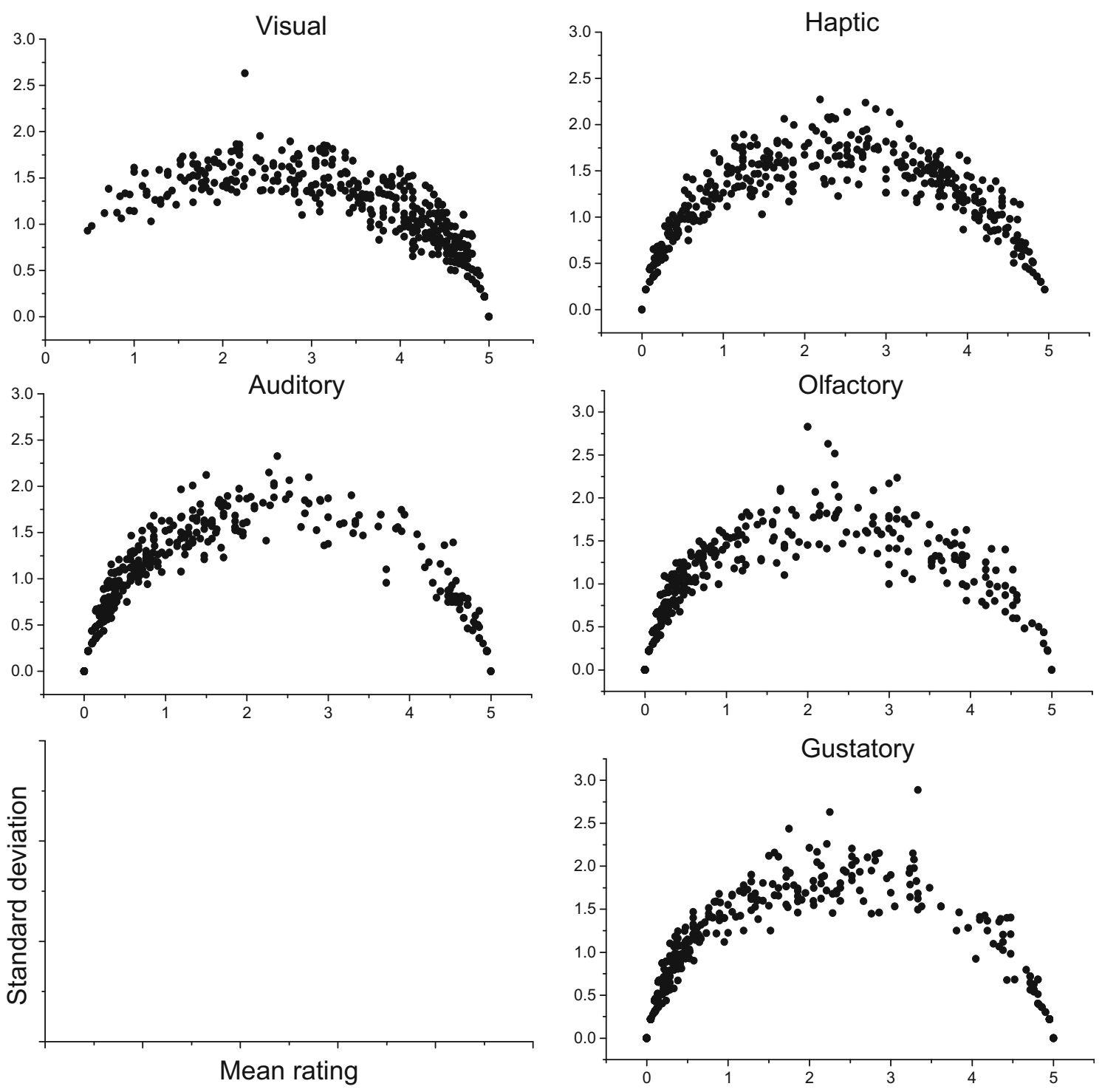

Fig. 10 Means and standard deviations of Lynott and Connell's (2012) modality exclusivity norms

think that we can ignore the fact that all of these datasets have the same problematic distribution. This is likely to be a result of the question that we ask participants when we generate these measures. When we present depth of sensorimotor experience as a scale, we are implicitly committing to the idea that is possible for an entity to be "half-real," or "half in space-time," or "half-seeable." The distributions of these semantic variables tell us that participants tend to reject this idea: They do not use midscale values.

One solution might be to specify explicitly what we want the middle of these scales to represent, and to provide examples of midscale words for participants so that they have something to anchor their judgments to. Whether something along these lines would usefully decrease variability in the middle of the scale is an open question, but a potential issue here is that it is very difficult (for me) to think of a construct that could serve as a midscale anchor between "concreteness" and "abstractness." More worryingly, given that there are relatively few words in the abstract half of the scale with low standard deviations, it could be that the concrete-abstract dichotomy is just not well formed.

Finally, I want to briefly discuss the distribution of emotional valence ratings. Emotional valence is different from the sensorimotor variables discussed above, in that it measures a completely separate dimension of experience. The standard deviation of an emotional valence rating also takes on a special importance because of how the scale is constructed. Figure 11 presents the means and standard deviations of the emotional valence scores from Warriner et al. (2013) $(n=$ 13,900). Warriner et al. presented this plot and touched on this issue, but they did not raise exactly the same point as the one I want to focus on here.

Recall that a score of 1 indicates extremely negative emotional valence, 5 indicates neutrality, and 9 indicates extremely 


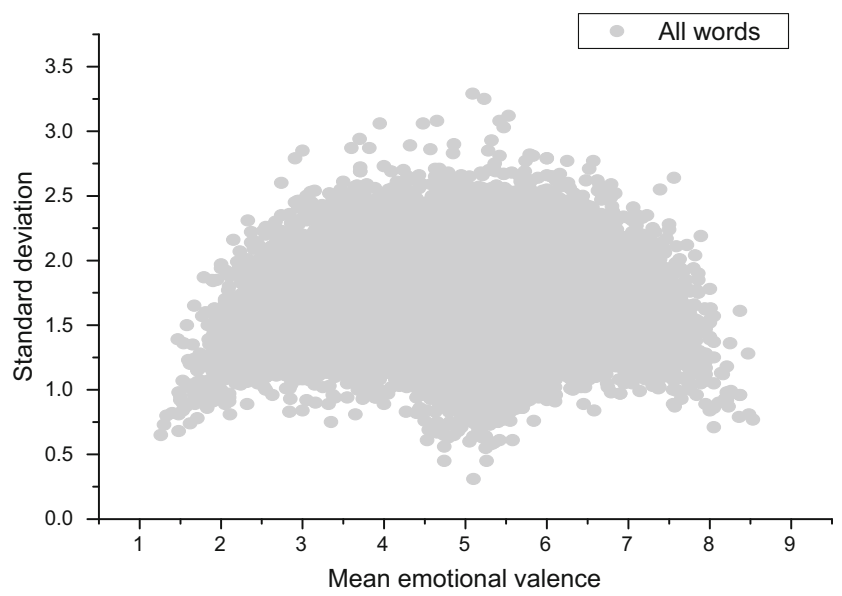

Fig. 11 Means and standard deviations of Warriner et al.'s (2013) emotional valence norms

positive emotional valence. Looking at Fig. 11, it should be possible to select unequivocally negative, neutral, and positive words for use in experiments: There are some words at mean ratings of 1,5 , and 9 with low standard deviations. This is obviously a good thing.

However, because the middle of this scale is a neutral point between two extremes, words with high standard deviations are especially problematic. This is because a 5 is supposed to indicate emotional neutrality. But if a word has a mean of 4-6 but a standard deviation of 2 or more, that means that on average, participants actually associate moderate to large emotional responses with that word. Some participants associate positive emotions with the word, but others associate negative emotions with it. Quite a few words look neutral, but in fact are not. A few examples are:

$$
\begin{aligned}
& \text { Cell: } \text { Mean }=4.09, S D=2.69 \\
& \text { Sushi: } \text { Mean }=6.25, S D=2.77 \\
& \text { Gym: } \text { Mean }=5.84, S D=2.52
\end{aligned}
$$

Similarly, if a word has a mean emotional valence of, say, 3 , but a standard deviation above 1.5 , that means that some people report a very strong negative response to that word, whereas some people report little or no emotional response at all. So if a researcher is interested in comparing responses to neutral words with responses to emotionally valenced words, they should definitely avoid words with high standard deviations for emotional valence, because they will add a significant amount of noise to the experimental design. One positive thing to note is that for the emotional valence measure, a high standard deviation is potentially problematic but is still interpretable. It makes sense that different people will associate different emotions with certain words. It also makes sense to think of our emotional responses as graded. I think this is a key difference between the sensorimotor experience variables and the emotional valence measure.

\section{Conclusion}

I have argued that there is a problem with the statistical characteristics of various semantic psycholinguistic variables (focusing in particular on the concreteness variable). In a great number of cases, mean values do not reflect the judgments that actual participants made about a word. Furthermore, mean values in the middle of these scales are difficult to interpret because it is not clear what property they indicate. Unfortunately, it appears that in many experiments reported throughout the literature on concreteness effects, many of the stimuli in the abstract conditions are not actually abstract. Instead, they are precisely those stimuli for which the mean concreteness value is a bad indicator of what participants' choices were. In two of the new list memory experiments reported here, no concreteness effect was obtained when the contrast in concreteness between conditions was maximized. However, when emotional valence was controlled, a concreteness effect was obtained in Experiment 3.

The concreteness effect obtained in Experiment 3 is encouraging, because it allays some of the concerns outlined above. However, there are still a number of reasons to be cautious about concreteness and other related semantic variables. First, the status of words with high standard deviations is entirely unclear. These high standard deviations for midscale words might arise at least partially because it is unintuitive to treat sensorimotor experience as a graded property. Second, only a very small number of "abstract" nouns have low standard deviations. This calls into question the utility of the concreteness-abstractness dichotomy as it is currently operationalized. Also, researchers who want to use nominal stimuli or control for word class have very little choice if they want to keep the standard deviations of their stimuli low. For the emotional valence measure, I think the picture is somewhat better. High standard deviations provide meaningful information, although it is perhaps even more important to keep standard deviations low when making comparisons between different areas of the scale.

The good news is that the use of new large-scale psycholinguistic databases such as the Brysbaert et al. (2013) concreteness norms and Warriner et al.'s (2013) emotional valence norms rather than relatively small, older databases (Coltheart, 1981) can allow researchers to sidestep the problems I raise completely. This is because the sheer size of these datasets allows for the selection of suitable stimuli.

Author note I thank Robyn Carston and Sebastian Crutch for their invaluable support in the preparation of the manuscript, and Matthew Jones for advice about R packages. I also thank three reviewers for advice and constructive criticism. All mistakes are entirely my own. This work was supported by the Economic and Social Research Council (grant number ES/J500185/1). 


\section{Appendices}

Table 14 1. Experiment 1 stimuli

\begin{tabular}{|c|c|c|c|c|c|c|c|c|c|}
\hline List & condition & Word 1 & Word 2 & Word 3 & Word 4 & Word 5 & Word 6 & Word 7 & Word 8 \\
\hline 1 & disagree & polling & dipstick & decade & centaur & exhaust & foreword & limbo & spender \\
\hline 2 & disagree & physic & sequel & deacon & nettle & output & earshot & deadline & cackle \\
\hline 3 & disagree & brethren & zenith & deluge & silence & lawsuit & theorist & polka & margin \\
\hline 4 & disagree & nappy & degree & panic & bearings & legend & request & physics & prefect \\
\hline 5 & disagree & sponsor & delta & dropper & phantom & egghead & rightness & aerial & eyesight \\
\hline 6 & disagree & halter & brainwave & mankind & nightlife & surname & scrounger & tunic & omen \\
\hline 7 & disagree & pariah & divorce & cosmos & sundries & purveyor & demon & crosswind & alias \\
\hline 8 & disagree & grammar & conveyance & easement & blackball & woodland & giantess & weeknight & instant \\
\hline 9 & disagree & tidbit & shallows & photon & plural & hallmark & grafting & sandman & nature \\
\hline 10 & disagree & slipstream & audit & poorhouse & minute & rival & tribune & abyss & spectrum \\
\hline 11 & agree & menace & bookie & tinting & flicker & rebound & squatter & tempo & pusher \\
\hline 12 & agree & uprise & digest & tiling & region & charmer & joyride & outbreak & nutrient \\
\hline 13 & agree & hubbub & matron & median & nuthouse & pullout & partner & distaste & refill \\
\hline 14 & agree & burial & backwash & mover & career & event & footing & caper & peacetime \\
\hline 15 & agree & jailbreak & torment & hazard & instinct & guru & downpour & richness & glucose \\
\hline 16 & agree & bunting & rhythm & stalker & dullness & ascent & headache & gunpoint & welfare \\
\hline 17 & agree & ringside & archduke & turmoil & shyness & posse & gangway & shipping & outreach \\
\hline 18 & agree & sunburst & mishap & bumpkin & deceit & villain & bloodlust & misdeed & hunting \\
\hline 19 & agree & diesel & roughhouse & attempt & whiner & viewpoint & freshness & stampede & leader \\
\hline 20 & agree & semblance & havoc & broadside & dining & image & dissent & goner & culprit \\
\hline 21 & abstract & setback & vagueness & spirit & notion & loyalty & esteem & phrasing & credence \\
\hline 22 & abstract & charade & rapture & betrayal & $\operatorname{logic}$ & backlash & renown & letdown & affront \\
\hline 23 & abstract & desire & mystique & intent & vantage & glory & nuance & unease & motive \\
\hline 24 & abstract & amends & prestige & godsend & satire & leeway & wordplay & pretense & calmness \\
\hline 25 & abstract & accord & whimsy & disdain & hardship & virtue & manner & regard & effect \\
\hline 26 & abstract & freelance & mischief & respite & folly & pureness & repute & courage & meantime \\
\hline 27 & abstract & merit & standpoint & future & allure & rapport & wisdom & prudence & insight \\
\hline 28 & abstract & mistake & quantum & dogma & function & purpose & willpower & hearsay & meaning \\
\hline 29 & abstract & patience & aspect & debut & fairness & pity & taboo & riddance & appeal \\
\hline 30 & abstract & piety & finesse & foresight & longshot & loathing & stigma & concern & control \\
\hline 31 & concrete & leaflet & roadhouse & artist & lighting & parsley & seabed & ironwork & lacrosse \\
\hline 32 & concrete & clipper & pewter & cauldron & quarry & blockade & earwig & clubfoot & logbook \\
\hline 33 & concrete & summit & breeches & abscess & foreman & award & entree & funnel & beacon \\
\hline 34 & concrete & corset & template & pigment & fuchsia & urchin & ringworm & crewman & mansion \\
\hline 35 & concrete & jester & gasket & sternum & backdrop & bouncer & chapel & resort & county \\
\hline 36 & concrete & penthouse & fracture & entrails & vinyl & buckskin & tundra & barrier & plumbing \\
\hline 37 & concrete & timepiece & methane & record & tiller & grindstone & merchant & shrapnel & duchess \\
\hline 38 & concrete & quarter & bulkhead & sarong & tenant & chamber & canon & bailiff & machine \\
\hline 39 & concrete & beaker & clinic & tango & clothing & amber & jackal & roulette & survey \\
\hline 40 & concrete & spiral & marrow & billiard & bootlace & scabies & saffron & captain & product \\
\hline
\end{tabular}


Table 15 2. Experiment 2 stimuli

\begin{tabular}{|c|c|c|c|}
\hline Pair & Condition & Word 1 & Word 2 \\
\hline 1 & concrete & cauldron & hike \\
\hline 2 & concrete & footman & band \\
\hline 3 & concrete & blazer & creature \\
\hline 4 & concrete & rubble & liqueur \\
\hline 5 & concrete & throttle & ulcer \\
\hline 6 & concrete & ranch & gauntlet \\
\hline 7 & concrete & cadet & concert \\
\hline 8 & concrete & ledge & manor \\
\hline 9 & abstract & betrayal & urge \\
\hline 10 & abstract & revenge & foresight \\
\hline 11 & abstract & godsend & risk \\
\hline 12 & abstract & wisdom & psyche \\
\hline 13 & abstract & hardship & malice \\
\hline 14 & abstract & greed & riddance \\
\hline 15 & abstract & loyalty & lenience \\
\hline 16 & abstract & bliss & mercy \\
\hline 17 & midscale & genius & royalty \\
\hline 18 & midscale & foreground & district \\
\hline 19 & midscale & gleam & patriot \\
\hline 20 & midscale & view & approach \\
\hline 21 & midscale & upstart & brawn \\
\hline 22 & midscale & expanse & profit \\
\hline 23 & midscale & asset & vortex \\
\hline 24 & midscale & habit & encore \\
\hline
\end{tabular}

Table 16 3. Experiment 3 stimuli

\begin{tabular}{|c|c|c|c|c|c|c|c|}
\hline List Number & Condition & Word 1 & Word 2 & Word 3 & Word 4 & Word 5 & Word 6 \\
\hline 1 & concrete & pad & harpoon & stretcher & kennel & ulcer & aftershave \\
\hline 2 & concrete & trachea & parsley & fuselage & rifleman & plaster & medallion \\
\hline 3 & concrete & cedar & rubble & trinket & composer & liver & dormitory \\
\hline 4 & concrete & scale & shipment & gladiator & guesthouse & morgue & marrow \\
\hline 5 & concrete & vineyard & porcelain & cocktail & warship & advisor & slate \\
\hline 6 & concrete & supervisor & infirmary & bouquet & manicure & bay & tomb \\
\hline 7 & concrete & graphics & sage & smoothie & wildfire & prosecutor & sapphire \\
\hline 8 & concrete & inspector & minefield & tourist & stub & horseradish & frostbite \\
\hline 9 & concrete & guitarist & notch & gauntlet & orphanage & vegetation & bomber \\
\hline 10 & concrete & greenhouse & sedative & museum & silicon & wreckage & accountant \\
\hline 11 & concrete & incubator & lavender & surgeon & violinist & courtroom & embroidery \\
\hline 12 & concrete & landlord & measles & dictator & pacemaker & minibus & plumber \\
\hline 13 & concrete & newsletter & bodyguard & stockbroker & foliage & petroleum & liqueur \\
\hline 14 & concrete & plantation & attorney & blockade & antibiotic & concert & currency \\
\hline 15 & concrete & stroke & titanium & bile & sniper & massage & adhesive \\
\hline 16 & abstract & urge & renown & patience & motive & malice & quandary \\
\hline 17 & abstract & penance & belief & indulgence & reproach & version & fixation \\
\hline 18 & abstract & mercy & glory & charade & aptitude & manner & formality \\
\hline 19 & abstract & risk & psyche & rhetoric & foresight & fraud & regard \\
\hline 20 & abstract & prudence & oblivion & hardship & $\operatorname{mood}$ & sarcasm & fate \\
\hline 21 & abstract & extent & imposition & purpose & competence & luck & whim \\
\hline 22 & abstract & willpower & bias & indecision & loyalty & seriousness & knowledge \\
\hline 23 & abstract & involvement & existence & coincidence & ruse & principles & betrayal \\
\hline 24 & abstract & detriment & subtlety & tradition & damnation & wisdom & fantasy \\
\hline 25 & abstract & forgiveness & semantics & value & sanctity & godsend & discretion \\
\hline 26 & abstract & eternity & politeness & concept & reasoning & anomaly & symbolism \\
\hline 27 & abstract & suspicion & goodness & arrogance & mortality & chance & theory \\
\hline 28 & abstract & precedent & privacy & likelihood & lunacy & oversight & revenge \\
\hline 29 & abstract & affirmative & repentance & leniency & similarity & merit & expertise \\
\hline 30 & abstract & wickedness & analogy & bliss & coercion & courage & avoidance \\
\hline 31 & midscale & plot & molecule & mankind & format & swindle & motherland \\
\hline 32 & midscale & hormone & reply & tarot & tribune & routine & pushover \\
\hline 33 & midscale & delay & gossip & slumber & bandwagon & response & vigilante \\
\hline
\end{tabular}


Table 16 (continued)

\begin{tabular}{|c|c|c|c|c|c|c|c|}
\hline List Number & Condition & Word 1 & Word 2 & Word 3 & Word 4 & Word 5 & Word 6 \\
\hline 34 & midscale & zone & shallows & pinnacle & wavelength & grief & degree \\
\hline 35 & midscale & envoy & character & fallout & clue & vacancy & tone \\
\hline 36 & midscale & circulation & drunkenness & midsummer & doctorate & goal & hoax \\
\hline 37 & midscale & cutthroat & rift & corporation & lawsuit & translation & sweetness \\
\hline 38 & midscale & announcement & activist & process & slack & formation & whiplash \\
\hline 39 & midscale & chronicle & monologue & overlap & motherhood & virus & penalty \\
\hline 40 & midscale & exhaustion & delegate & magic & rebuttal & crackpot & diversion \\
\hline 41 & midscale & entirety & ugliness & factor & ancestry & confidant & purgatory \\
\hline 42 & midscale & engagement & accident & insomnia & regulator & utility & egghead \\
\hline 43 & midscale & repellent & takeover & provision & dioxide & offence & thinker \\
\hline 44 & midscale & equivalent & oracle & ignition & visibility & ransom & narrative \\
\hline 45 & midscale & sense & extremity & content & lunatic & divorce & casualty \\
\hline
\end{tabular}

Open Access This article is distributed under the terms of the Creative Commons Attribution 4.0 International License (http:// creativecommons.org/licenses/by/4.0/), which permits unrestricted use, distribution, and reproduction in any medium, provided you give appropriate credit to the original author(s) and the source, provide a link to the Creative Commons license, and indicate if changes were made.

\section{References}

Allen, R., \& Hulme, C. (2006). Speech and language processing mechanisms in verbal serial recall. Journal of Memory and Language, 55, 64-88. doi:10.1016/j.jml.2006.02.002

Balota, D. A., Yap, M. J., Hutchison, K. A., Cortese, M. J., Kessler, B., Loftis, B.,...Treiman, R. (2007). The English Lexicon Project. Behavior Research Methods, 39, 445-459. doi:10.3758/ BF03193014

Bates, D., Mächler, M., Bolker, B., \& Walker, S. (2015). Fitting linear mixed-effects models using lme4. Journal of Statistical Software, 67, 1-48. doi:10.18637/jss.v067.i01

Begg, I. (1972). Recall of meaningful phrases. Journal of Verbal Learning and Verbal Behavior, 11, 431-439. doi:10.1016/S0022537180024-0

Binder, J. R., Westbury, C. F., McKiernan, K. A., Possing, E. T., \& Medler, D. A. (2005). Distinct brain systems for processing concrete and abstract concepts. Journal of Cognitive Neuroscience, 17, 905917.

Bleasdale, F. A. (1987). Concreteness-dependent associative priming: Separate lexical organization for concrete and abstract words. Journal of Experimental Psychology: Learning, Memory, and Cognition, 13, 582-594. doi:10.1037/0278-7393.13.4.582

Brysbaert, M., Stevens, M., Mandera, P., \& Keuleers, E. (2016). The impact of word prevalence on lexical decision times: Evidence from the Dutch Lexicon Project 2. Journal of Experimental Psychology: Human Perception and Performance, 42, 441-458. doi:10.1037/ xhp0000159

Brysbaert, M., Warriner, A. B., \& Kuperman, V. (2013). Concreteness ratings for 40 thousand generally known English word lemmas. Behavior Research Methods, 46, 904-911. doi:10.3758/s13428013-0403-5

Coltheart, M. (1981). The MRC psycholinguistic database. Quarterly Journal of Experimental Psychology, 33A, 497-505. doi:10.1080/ 14640748108400805

Cortese, M. J., \& Fugett, A. (2004). Imageability ratings for 3,000 monosyllabic words. Behavior Research Methods, Instruments, \& Computers, 36, 384-387. doi:10.3758/BF03195585
Crutch, S. J., \& Warrington, E. K. (2005). Abstract and concrete concepts have structurally different representational frameworks. Brain, 128, 615-627. doi:10.1093/brain/awh349

de Groot, A. M. (1989). Representational aspects of word imageability and word frequency as assessed through word association. Journal of Experimental Psychology: Learning, Memory, and Cognition, 15, 824-845. doi:10.1037/0278-7393.15.5.824

Dhond, R. P., Witzel, T., Dale, A. M., \& Halgren, E. (2007). Spatiotemporal cortical dynamics underlying abstract and concrete word reading. Human Brain Mapping, 28, 355-362. doi:10.1002/ hbm. 20282

Gee, N. R., Nelson, D. L., \& Krawczyk, D. (1999). Is the concreteness effect a result of underlying network interconnectivity? Journal of Memory and Language, 40, 479-497. doi:10.1006/jmla.1998.2627

Huang, H.-W., Lee, C.-L., \& Federmeier, K. D. (2010). Imagine that! ERPs provide evidence for distinct hemispheric contributions to the processing of concrete and abstract concepts. NeuroImage, 49, 1116-1123. doi:10.1016/j.neuroimage.2009.07.031

Jager, B., \& Cleland, A. A. (2016). Polysemy advantage with abstract but not concrete words. Journal of Psycholinguistic Research, 45, 143156. doi:10.1007/s10936-014-9337-z

James, C. T. (1975). The role of semantic information in lexical decisions. Journal of Experimental Psychology: Human Perception and Performance, 1, 130-136. doi:10.1037/0096-1523.1.2.130

Kounios, J., \& Holcomb, P. J. (1994). Concreteness effects in semantic processing: ERP evidence supporting dual-coding theory. Journal of Experimental Psychology: Learning, Memory, and Cognition, 20, 804-823. doi:10.1037/0278-7393.20.4.804

Kousta, S.-T., Vigliocco, G., Vinson, D. P., Andrews, M., \& Del Campo, E. (2011). The representation of abstract words: Why emotion matters. Journal of Experimental Psychology: General, 140, 14-34. doi:10.1037/a0021446

Kousta, S.-T., Vinson, D. P., \& Vigliocco, G. (2009). Emotion words, regardless of polarity, have a processing advantage over neutral words. Cognition, 112, 473-481. doi:10.1016/j.cognition.2009.06. 007

Kroll, J., \& Merves, J. (1985). Lexical access for concrete and abstract words. Journal of Experimental Psychology: Learning, Memory, and Cognition, 12, 92-107. doi:10.1037/0278-7393.12.1.92

Kruschke, J. K. (2011). Bayesian assessment of null values via parameter estimation and model comparison. Perspectives on Psychological Science, 6, 299-312. doi:10.1177/1745691611406925

Kuperman, V., Stadthagen-Gonzalez, H., \& Brysbaert, M. (2012). Ageof-acquisition ratings for 30,000 English words. Behavior Research Methods, 44, 978-990. doi:10.3758/s13428-012-0210-4

Kuznetsova, A., Brockhoff, P. B., \& Christensen, H. B. (2015). lmerTest: Tests in linear mixed effect models (Software). Retrieved from http://cran.r-project.org/package=lmerTest 
Lee, C., \& Federmeier, K. D. (2008). To watch, to see, and to differ: An event-related potential study of concreteness effects as a function of word class and lexical ambiguity. Brain and Language, 104, 145158. doi:10.1016/j.bandl.2007.06.002

Lynott, D., \& Connell, L. (2012). Modality exclusivity norms for 400 nouns: The relationship between perceptual experience and surface word form. Behavior Research Methods, 45, 516-526. doi:10.3758/ s13428-012-0267-0

Marschark, M., \& Hunt, R. R. (1989). A reexamination of the role of imagery in learning and memory. Journal of Experimental Psychology, 15, 710-720.

Miller, L. M., \& Roodenrys, S. (2009). The interaction of word frequency and concreteness in immediate serial recall. Memory \& Cognition, 37, 850-865. doi:10.3758/MC.37.6.850

Morey, R. D., Rouder, J. N., \& Jamil, T. (2015). BayesFactor: Computation of Bayes factors for common designs (version 0.9.12-2). Retrieved from https://rdrr.io/cran/BayesFactor/

Nelson, D. L., \& Schreiber, T. A. (1992). Word concreteness and word structure as independent determinants of recall. Journal of Memory and Language, 31, 237-260. doi:10.1016/0749-596X(92)90013-N

Paivio, A., Khan, M., \& Begg, I. (2000). Concreteness and relational effects on recall of adjective-noun pairs. Canadian Journal of Experimental Psychology, 54, 149-160.

Paivio, A., Walsh, M., \& Bons, T. (1994). Concreteness effects on memory: When and why? Journal of Experimental Psychology: Learning, Memory, and Cognition, 20, 1196-1204. doi:10.1037/ 0278-7393.20.5.1196

Paivio, A., Yuille, J. C., \& Madigan, S. A. (1968). Concreteness, imagery, and meaningfulness values for 925 nouns. Journal of Experimental Psychology, 76(1, Pt. 2), 1-25. doi:10.1037/h0025327

Pexman, P. M., Hargreaves, I. S., Edwards, J. D., Henry, L. C., \& Goodyear, B. G. (2007). Neural Correlates of Concreteness in Semantic Categorization. Journal of Cognitive Neuroscience, 19, 1407-1419. doi:10.1162/jocn.2007.19.8.1407
Romani, C., McAlpine, S., \& Martin, R. (2008). Concreteness effects in different tasks: Implications for models of short-term memory. Quarterly Journal of Experimental Psychology, 61, 292-323. doi: 10.1080/17470210601147747

Sabsevitz, D. S., Medler, D. A., Seidenberg, M., \& Binder, J. R. (2005). Modulation of the semantic system by word imageability. NeuroImage, 27, 188-200. doi:10.1016/j.neuroimage.2005.04.012

Sadoski, M., Kealy, W. A., Goetz, E. T., \& Paivio, A. (1997). Concreteness and imagery effects in the written composition of definitions. Journal of Educational Psychology, 89, 518-526. doi:10. 1037/0022-0663.89.3.518

Schock, J., Cortese, M. J., \& Khanna, M. M. (2012). Imageability estimates for 3,000 disyllabic words. Behavior Research Methods, 44, 374-379. doi:10.3758/s13428-011-0162-0

Skipper-Kallal, L. M., Mirman, D., \& Olson, I. R. (2015). Converging evidence from fMRI and aphasia that the left temporoparietal cortex has an essential role in representing abstract semantic knowledge. Cortex, 69, 104-120. doi:10.1016/j.cortex.2015.04.021

ter Doest, L., \& Semin, G. (2005). Retrieval contexts and the concreteness effect: Dissociations in memory for concrete and abstract words. European Journal of Cognitive Psychology, 17, 859-881. doi:10. 1080/09541440540000031

van Casteren, M., \& Davis, M. H. (2007). Match: A program to assist in matching the conditions of factorial experiments. Behavior Research Methods, 39, 973-978. doi:10.3758/BF03192992

Walker, I., \& Hulme, C. (1999). Concrete words are easier to recall than abstract words: Evidence for a semantic contribution to short-term serial recall. Journal of Experimental Psychology: Learning, Memory, and Cognition, 25, 1256-1271. doi:10.1037/0278-7393. 25.5.1256

Warriner, A. B., Kuperman, V., \& Brysbaert, M. (2013). Norms of valence, arousal, and dominance for 13,915 English lemmas. Behavior Research Methods, 45, 1191-1207. doi:10.3758/s13428-012-0314-x 